Complexity, Pedagogy and the Economics of Muddling Through by

\author{
Buz Brock \\ and \\ David Colander
}

June 2008

MIDDLEBURY COLLEGE ECONOMICS DISCUSSION PAPER NO. 08-05

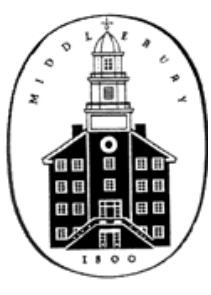

DEPARTMENT OF ECONOMICS

MIDDLEBURY COLLEGE

MIDDLEBURY, VERMONT 05753

http://www.middlebury.edu/ econ 


\section{Complexity, Pedagogy, and the Economics of Muddling Through}

\section{By Buz Brock and David Colander}

\section{Preliminary Draft}

\section{This paper was first presented at the AEA meetings on complexity. It was later published in a book edited by Massimo Alszano nad Alan Kirman, Economics: Complex Windows, Springer Publishers)}

Economics has evolved significantly since the 1950s, both in what it covers and the approaches it uses. Whereas the applied policy economics through the 1950s could reasonably be called neoclassical, modern economics has outgrown that classification. Its approach is more eclectic, and its applied policy models are not required to adhere to the assumptions that Solow calls the holy trinity--rationality, equilibrium, and greed. (See Kreps (1997) for a discussion.)

The welfare economics underlying applied policy has not evolved at the same pace. We still teach students, and implicitly base policy discussions on, a welfare economics that evolved out of the neoclassical mold-built on a foundation of Pareto optimality, externalities, and Walrasian general equilibrium. The essence of that welfare economics for pedagogical purposes is captured in Abba Lerner's "economic of control" metaphor. In it economists' underlying general equilibrium model, based on the holy trinity, serves as a map for the economy; the applied policy problem is to get a workable steering wheel on the car, a reasonable driver, and decent linkages. In essence the goal is to design policy, or, in sophisticated presentations, policy rules, to get the car to follow the map. In a nutshell: theory points out the way to go; applied policy deals with getting you there.

In the economics of control vision the Arrow Debreu McKenzie Walrasian general equilibrium model provides the correct set of prices or targets. (In advanced models, the target prices could be specified as dynamic stochastic variables.) The job of applied policy economists is to specify those prices with their model and to design general rules of policy, and policy instruments, to achieve those prices. 
Recent work in complexity science, which sees the economy as a complex system such as that found in Arthur, Durlauf, and Lane (1997) suggests a different welfare framework within which to consider applied policy. This complexity work is part of a broader shift away from the holy trinity that is occurring in modern economics. In applied work, and in some theoretical work, more general assumptions are replacing the more narrowly specified holy trinity assumptions. Specifically, more general forms of purposeful behavior are replacing simple "greed"; cognitive awareness is replacing simple rationality; and sustainability is replacing simple equilibrium. In the complexity approach the economy is thought of as a self-organizing system that structures communication patterns among agents. ${ }^{1}$

The work done at CeNDEF (http://www.fee.uva.nl/cendef) is an example of the approach we have in mind. Researchers there are combining new and old strategies to address fundamental questions. For example their theoretical work is calibrated to reproduce many features of real world data, but is based on heterogeneous agents with differing degrees of rationality, rather than on homogeneous agents. Their choice of assumptions is further governed by experimental and econometric work using field data. They study how changing the degree (e.g., the "dial") of rationality creates dynamical patterns in their artificial economies, which are then compared to dynamical patterns observed in actual economies. They use complexity tools such as bifurcation theory to study these pattern-generating mechanisms analytically as well as computationally.

Viewing the economy as a complex system suggests the need for some modifications in the underlying welfare foundations for applied policy work. The "right price” economic of control view of applied policy does not fit the complexity approach. The complexity approach places more emphasis on the "right price process" rather than the "right price". The complexity approach also differs from earlier approaches that took complexity seriously, such as the "Austrian" approach. That Austrian approach also stressed the "right price process" view of policy, but it was perceived as opposing formal modeling and econometric work. The modern complexity approach is intricately involved in modeling and econometric work. It uses computationally assisted model building, analytics, and econometrics, to move the discussion in a more quantitative direction than that favored by Austrians. It pushes mathematical methods to the limit, using analytical and computational tools such as bifurcation theory, interacting systems theory, and hierarchies of temporal and spatial scales.

Even with these methods the complexity approach does not achieve the understanding needed to base policy on the "right price" view. If the economy is a complex system there is no definitive map for the economy. Novelty may continually develop, making the economy, in a fundamental sense, non-ergodic. When working on microfoundations of complex systems, researchers must pay close attention to issues like temporal and spatial variations in the interconnection structure of the economy and the potential of such issues to create abrupt and "surprising" changes.

${ }^{1}$ Defining complexity is too complex a task to deal with here, other than to say that we are here using an inclusive definition that includes a variety of different approaches. For a discussion of the definition of complexity see Brock (2000a) and Arthur, Durlauf and Lane (1997). 
When one faces seriously the econometric problems of identifying the "true" causal pathways in a system with important observable and unobservable heterogeneity at various temporal and spatial scales (where "space" is taken in the wide sense) the best policy makers can do is to determine temporary patterns that may allow for exploitable policy opportunities while keeping a careful outlook for the potential of "surprises". To prepare students to deal with the complexity modern researchers are dealing with, we need to teach them a welfare economics that allows for that complexity. We call this modified approach to welfare economics the economics of muddling through because muddling through is, in the immediate future, the best one can hope for as a policy objective.

In this paper we offer some initial explorations of how the welfare foundations of economic policy might change if welfare theory started from the premise that the economy is a complex system. Our discussion is directed at non-specialists in complexity. Its purpose is to provide some insight into why the complexity revolution is more than the latest toy of mathematical economists-more than a method of increasing the mathematical complexity of studying economics. It has, we argue, important policy implications that will make a difference in how applied policy economist work, the methods they use, and how they think about their policy work.

Specifically, we discuss four types of changes in applied policy that we believe follow from this complexity foundation. They are:

1) Changes in the degree of certainty with which policy advice is presented.

2) Changes in the methods of examining policy alternatives.

3) Changes in the nature of the policy questions asked.

4) Changes in the nature of the general policy solutions.

Before we explore these we briefly discuss the way in which modern economics uses welfare economics in practice.

\section{How Modern Economics uses Welfare Economics in Practice}

Modern economics is very much about policy. The majority of economists are applied economists who see their job as taking received economic wisdom embodied in a set of canonical models and applying that wisdom to specific cases. That application is highly empirical, and, by mathematical standards, not very formal, although to a humanist, it certainly looks formal. Robert Solow (1997) has captured the essence of the current approach with his "loose fitting positivism” terminology. He writes:

Today, if you ask a mainstream economist a question about almost any aspect of economic life, the response will be: suppose we model that situation and see what happens....There are thousands of examples; the point is that modern mainstream economics consists of little else but examples of this process. (p. 43) 
The positivism of modern economics is embodied in its focus on empirical testing and its methodological adherence to the separation of positive and normative elements. It is "loose fitting" positivism because the actual policy models used often have only a slight connection to the pure theoretical models that currently form the general equilibrium core of the theory of welfare economics. The theoretical welfare models provide the framework for thinking about policy, but that framework is not seen as limiting the assumptions made in the actual applied policy models.

Modern microeconomics uses an eclectic set of models that employ a variety of assumptions and methods. For example, the formal general equilibrium model provides no learning by doing, or feedback of activity on tastes; it takes tastes as a primitive. Applied policy models, however, such as those of Robert Frank (1999),can take tastes as a variable. Another example concerns rationality; formal general equilibrium models assume strong rationality; many applied policy models assume bounded rationality when that assumption provides a better fit with the data. George Akerlof's (1993) cognitive dissonance model of interrelationships and Robert Solow's (1990) sociological model of the labor market are examples. Yet another example is in finance where psychological assumptions are replacing strong rationality assumption. This has occurred so much that Richard Thaler (1999) argues, that soon, “the term 'behavioral finance' will be correctly viewed as a redundant phrase. What other kind of finance is there?”

The "tight fitting positivism” limitations on applied policy modeling, requiring the assumptions of applied policy models to be consistent with the assumptions of the formal general equilibrium core, are gone. In modern applied policy the choice of assumptions are generally made on empirical grounds: if it provides a better fit with the data, especially out-of-sample data, while maintaining a tractable model, it is a better model.

These examples demonstrate a major split that has developed between most formal general equilibrium models, where assumptions are generally chosen to create global tractability, and applied policy models, where assumptions are generally chosen to create a type of local model tractability, but still achieve an empirical fit with the evidence.

The differing assumptions of core general equilibrium theories and applied policy models presents a consistency problem for the welfare foundations of applied economics. Economists' detailed work on welfare theory, and the standard welfare propositions that follow from that work, can serve as a firm basis of applied policies only for those tightfitted models that share the assumptions of its formal general equilibrium core. Applied policy models using different assumptions from the formally developed general equilibrium theory must implicitly make a robustness assumption if the welfare theory associated with that general equilibrium theory is to serve as a backdrop for policy. Loose fitting positivism requires strong robustness assumptions.

The eclectic modeling, applied policy approach has evolved over the last thirty years as micro economists reacted to objections that it was too concerned with pure theory and logical models. It is a pragmatic approach that has been fought by purists, 
who have pointed out the above-mentioned consistency problem. Purists argue that the eclectic models are ad hoc and unreliable; they argue that all applied work should use the same assumptions as the developed core general equilibrium theory: If you use the welfare theory, you should use the holy trinity of assumptions upon which it is based. The pragmatic approach developed, nonetheless, because of the usefulness of these eclectic, ad hoc models and the generally perceived failure of purists to provide acceptable real-world policy linkages in the absence of such ad hoc models.

For example, consider DeLong's "What's Wrong with Our Bloody Economies?" (http://econ161.berkeley.edu/ created 1/11/98) where he discusses recent financial crises and footloose capital movements. He states: "The root cause of the crises is a sudden change of state in international investors' opinions. Like a herd of not-very-smart cattle, they all were going one way in 1993 or 1996, and then they turned around and are all going the opposite way today...The correct answer....the market was manic....not a cool judgment of changing fundamentals but instead a sudden psychological victory of fear over greed." After a discussion of the enormous benefits of free flowing capital, while mentioning caveats about the problems (like the above) caused by such enormous amounts of footloose capital DeLong suggests we look at three basic policy rules coined by W. Bagehot long ago: (i) Make Lenders of Last Resort available; (ii) Make it painful to be bailed out; (iii) Don't bail anyone out unless they are solvent if there were not a panic.

Whether one agrees with DeLong or not, it is hard to find better guidance than Bagehot's from our conventional textbook general equilibrium model towards a useful policy posture in financial panic management. This is not to say that we cannot model it in intertemporal general equilibrium models. With jump variables (e.g. Turnovsky (1995) one can create patterns that look like "panics" but are, in fact, just rational expectations equilibrium responses to changes in underlying fundamental parameters unobservable to the econometrician. But in financial panic management the abrupt changes in asset prices and the magnitude of financial movements seem difficult to link to any financial rational expectations "jump variable" at the "right" time scale.

Complexity models of financial asset pricing with social interactions (e.g. Brock (1993)) provide a better fit with DeLong and Bahehot's educated common sense policy precepts. They stress the ability of observable and unobservable correlations propagated through the financial community's interaction structure to create not only alternative states but also lightning quick changes of state via a breakdown of the usual smoothing effects of something like a Law of Large Numbers.

Writers like Prigogine have stressed the link between breakdowns of phenomena like Laws of Large Numbers and complexity-type behavior such as bifurcations and emergent structures for years. See for example, his paper in Day and Chen (1993). These abrupt changes can be triggered by minute unobservables undetectable by an observing scientist. Basically this phenomenon happens because a certain infinite series of appropriate "spatial" cross correlations amongst agents fails to converge absolutely in a large system of agents. This type of complexity-based approach to studying asset pricing 
and trading volume seems to be appropriate in our huge highly interconnected (via "on line" trading engines and news feeds) financial trading system assisted by current electronics.

In our view the problem of current applied theory is not so much that it is ad hoc and does not follow a particular model, e.g. the extended general equilibrium model faithfully. The problem is that it too closely ties its welfare foundation to the current general equilibrium core without modifying that core to include complexity-based features like a temporal/spatial hierarchy of interconnective elements amongst the agents. These elements can create "policy surprises" in the real world that the core is not good at training the analyst to watch out for. To help solve the problem we suggest that loose fitting positivism be replaced by loose fitting pragmatism, based upon a broader complexity view of the economy. Loose fitting pragmatism starts from the proposition that any model is inherently ad hoc, but it attempts to limit that adhocness and take it into account in its policy advice.

Let us now turn to four differences we see following from seeing welfare economics as a type of muddling through, rather than as part of the economics of control.

\section{1) Changes in the degree of certainty with which policy advice is presented.}

Above, we argued that there is often a false sense of connection between the policy advice economists give based on ad hoc models and the underlying welfare economics. In the complexity welfare framework that connection is given up. Pure theory can say very little definitively about complex systems. It may be able to add insights to intuition; it may temporarily provide an acceptable fit upon which one can tentatively base policy. But there always remains an underlying uncertainty-the possibility that the system might change in ways that cannot be currently modeled or created-that must be taken into account in designing policy. In complexity uncertainty is part of the core theory. Currently, in much applied policy work, while uncertainty is recognized, it often is not given much weight. Specifically, we suggest that uncertainty has an important implication for policy design and policy focus, as we will discuss below.

Our argument is not that we have to throw out all current work that is based on the current general equilibrium core. It is simply that standard welfare economics underlying applied policy work gives too much reverence to it. Loose fitting pragmatism allows the Arrow-Debreu-McKenzie Walrasian general equilibrium core to be used, but without the reverence. It is useful in guiding models in those cases where the assumptions provide an acceptable match to reality. But the complexity approach also allows the use of other currently implicit general equilibrium models with different assumptions. In short the general equilibrium cores is seen as a useful, pragmatic model, and not as the single model that defines the core assumptions that must be used. Theoretical researchers are currently working on broadening and modifying the benchmark Arrow Debreu model. But no clearly defined alternatives have been developed, and without a clearly defined alternative, the Arrow Debreu model has remained the benchmark of welfare economics. 
Integrating this uncertainty into applied policy will require new techniques such as computational Bayesian techniques and Bayesian Model Averaging (e.g. Geweke (1999), Brock and Durlauf (2000b), Brock and Carpenter (2000a)). Technically, these new techniques allow for the possibility of data to speak to the presence of alternative stable states and to the measure the added impact of this possibility upon the posterior distribution of welfare measures in a dynamical system where alternative stable states are a serious potential possibility.

The advantage of a Bayesian framework is that it produces automatically, as a byproduct, a theory of the burden of proof in the form of a potential precautionary principle in the quantitative form of a Bayesian posterior welfare distribution. For example Pizer (1996) produces a quantitative expression for how much the case for caution in climate change policy is strengthened when uncertainty is taken into account. The uncertainty in the evidence leads to a strengthened case (relative to "best-guess" parameter values) for emission reductions and to an increased preference for flexible regulatory/management modes and gives a quantitative expression for each.

Brock and Durlauf (2000b) and Brock and Carpenter (2000a) have considered a start on this kind of work in the context of growth econometrics and dynamic management of ecosystems by using formal treatments of model uncertainty in the Bayesian literature. As shown by Brock and Durlauf (2000b) adjustment for model uncertainty (even when that uncertainty is constrained by theory) as well as Knightian Uncertainty causes an increase in the level of modesty which is probably appropriate when giving advice given our current level of science. It also allows data to speak to theoretical debates in a statistically sensible way by forcing each side to submit a model class that represents their theory to a Bayes type procedure that allows the data to attach posterior odds to the truth of each theory. Computational advances have now allowed such methods to be operationalized. Brock and Carpenter (2000) use a dynamic treatment where there is the complicating factor of two-way feedback between the management and the model selection and estimation process with the extra complication of possible alternative stable states in the underlying system dynamics.

It is likely that adjustment for uncertainty in the more realistic manner being suggested here will strengthen the case for adaptive management based upon monitoring of "expert leading indicators of systemic health." In ecology this would mean focusing policy analysis on populations of organisms sensitive to changes of relevant state and especially informative organism populations signatory of an impending "poised"-"near bifurcational" state. In economies it might mean focusing policy analysis on certain sociological indicators, such as suicides of youth, surveys and other measures of "wellbeing" as stressed by the hedonic economic psychologists cited in Frank (1999) to estimate when the anomie of a system has increased to a near bifurcation state. It suggests that applied economists should develop continuously updated quantitative value indices of such leading indicators presented in a form for immediate use by policymakers who must face compromise tradeoffs and who must face the decision whether the gains from a policy change are worth the costs of promoting it. 
The complexity foundation to welfare economics also has some more general implications for thinking about the advantages of market systems. Specifically, it presents modified welfare foundations for markets than those suggested by standard welfare theory. For example simulations and analytics (cf. SFI II) suggest that, complex systems can self-organize, after application of policy action, in surprising ways in contrast to the predictions of conventional comparative statics exercises. They can also manage quite well--going along as they have gone along with no central controller. In such cases there is a slight status quo (not a perfectly competitive market) bias in the complexity approach because the status quo has, by its existence, shown that it is a feasible solution. Other states may not be. (For a discussion see Brock and Colander (2000).)

Whether the status quo is optimal in any sense is a much harder question since many equilibria are possible. Moreover, as we will discuss below, global optimality is reduced in importance when taking a complexity perspective as other attributes, such as resilience and sustainability, are directly considered as policy goals.

\section{2) Changes in the methods of modeling policy alternatives}

If less certainty were all one could say about the policy implications of complexity, it would not be worth discussing. But approaching policy from a complexity framework does more than simply build in the uncertainty of policy. It suggests significantly different methods be used in designing policy, and in designing policy research. Let us list and briefly discuss some of the most important of these.

More use of nonlinear dynamics and recursive mathematics.

The first difference between modeling in the standard approach and modeling in a complexity approach is that complexity approach is the mathematics used. Complexity focuses more on non-linear dynamics and recursive mathematics than does the standard approach. Non-linear models typically lead to multiple equilibria, sunspot, and pathdependent models involving sudden regime shifts. Thus, these models are more emphasized in the complexity work. Standard applied economics gets to these type of models, but the path is not so direct, and it is only with reluctance. (Schumpeter (1954) argued that unique equilibrium models were essential to doing economics as a science.)

Consistent with the use of these techniques there would be a stronger focus of theoretical work on model and equilibrium selection mechanisms, as well as broader dynamic concepts of equilibrium. (See Blume (1997), Brock and Durlauf (2000a), and Brock (2000b).

\section{More Focus on computational work}

The difference in mathematics used is associated with another important difference in approach. Researchers using a complexity approach to economics are more willing to use techniques that provide insight into issues but do not lead to full analytic solutions. The reason standard economics does not use non-linear mathematics is that 
such models are generally analytically intractable. Whereas in standard approaches analytic tractability is a key component, in the complexity approach, analytic tractability is not an absolute requirement because now computational advances have been made that allow us to deal with economic models closer to the complex systems that may permeate real economies (Judd (1998)).

\section{More use of Simulations and Agent based models.}

In standard economics, computational methods are used to gain insight into general equilibrium issues (i.e. computable general equilibrium models) The complexity approach suggests a broader role for computational methods. It sees important insights into the problems being gained via simulations and agent-based modeling starting from scratch. In essence one "grows" the economy rather than formally models it. Such agentbased modeling is a quite different approach to thinking about policy. There is increasing interest in agent-based computational economics (ACE), the computational study of economies modeled as evolving systems of autonomous interacting agents. (See http://www.econ.iastate.edu/tesfatsi/ace.htm). Agent-based modeling presents a whole new set of problems; solving them is central to the complexity approach to welfare economics, whereas they are tangential to standard welfare economics.

\section{Assumptions are Determined Empirically to Fit the Data}

All the above differences are associated with a difference in the way one conceives of designing a model. In the standard approach one designs a model deductively, following core assumptions. The complexity approach eliminates any particular general equilibrium model as the background-coordinating model of the economy and replaces it with a broader set of, often-implicit, general equilibrium models whose assumptions are determined through backward through induction from the assumptions that fit the data in applied policy work. An example here is the work of Brock and Hommes (1998) in their work on alternatives to the efficient market hypothesis. In that work they explore the implications of the heterogeneous market hypothesis.

In the complexity approach both abstract theory and simulation work provide stories that are used to check the compatibility of narrower applied-policy stories that form the basis of applied policy work. In the complexity approach the core general equilibrium model must be designed to be consistent with the applied policy work, not the other way around. For example, if applied policy work suggests that positional consumption goods are important, then we need the core to include assumptions that allow positional consumption. That unknown core should be given as much initial weight in policy choice as is current general equilibrium propositions. 
By using the Bayesian Model Averaging tools used in Brock and Durlauf (2000b), as well as the integration of econometrical and theoretical tools of "InteractionsBased Models" (e.g., Brock and Durlauf (2000a), one could attach posterior odds to modifications of that core, and possibly model dealing with unknown parts of the "true core" by formal treatments of "ambiguity" like Knightian Uncertainty. ${ }^{2}$

\section{Justifying Assumptions}

The ability to choose assumptions to fit with applied work's focus on relating theory to data does not provide a free ride. Along with that flexibility comes a set of limitations on assumptions and a reduction in the degree of certainty attached to the model; assumptions cannot be chosen in an ad hoc manner; each must be justified as being appropriate. Justification of ad-hoc assumptions is often missing in current applied work even though the assumptions often differ from general equilibrium assumptions, creating the consistency problem discussed above. The acceptance of the need for justification would make the consistency problem a key issue in discussions of policy models, and hence would represent a major change in how applied-policy work is done.

The new methods discussed above, such as agent based modeling, offer one way of justifying assumptions. There are others, including experimental work--showing that the assumption is consistent with how people actually behave--and importing behavioral assumptions that have been developed by researchers in experimental and behavioral psychology.

Four desirable requirements for assumptions used in policy models include the following:

(1) Intuitive plausibility

In complexity, one does not use induction or deduction; instead one uses a combination of the two--what the pragmatist, Charles Pierce, called abduction. In abduction the best one can do in theory is to tell intuitively plausible stories. Notice that this is a quite different use of intuitive plausibility than that found in the calibration literature. In that literature the assumptions need not be intuitively plausible; the intuitively plausibility focus is on the ability of the calibrated models to reproduce relevant empirical regularities. That requirement still exists but the additional requirement that fits the complexity approach is that the model's assumptions reasonably match the assumed characteristics of the agents in the observable system. Thus, we would argue that representative agent models in macro-economic work do not meet the intuitive plausibility requirement, even if they can be calibrated to the relevant empirical regularities because (i) researchers have essentially harvested already most of the useful macro economic insights available from such models; and (ii) the "Gorman" type conditions for existence of such an "as if" agent, even if extended to some type of large system limit framework, do not seem all that promising to add future value, especially

${ }^{2}$ See Brock and Durlauf (2000b) as well as work by Larry Epstein ( ), Lars Hansen ( ), and Thomas Sargent ( )along these lines. 
given the large volume of observed trading amongst agents. Heterogeneity and interaction of agents is important on an intuitive level, and thus cannot be ignored.

We do not want to claim too much for this requirement. What is intuitively plausible is clearly an ambiguous criteria, and "intuitively plausible" is more effective at ruling out general models, than it is in choosing among them.

(2) Empirically relevant

Science is about efficiently storing and summarizing patterns in data, and putting those patterns together to better understand, and possibly predict, patterns that otherwise would not be observable. Based on arguments such as Friedman's F-twist, standard economics has emphasized the latter part of definition, and has focused on choosing whatever assumptions are necessary to best predict new patterns. Assumptions that predict "best" are the best assumptions. The problem is that empirically determining what predicts best is difficult, if not impossible, which has left standard economics free to use the holy trilogy with the argument that they predict as well as anything else.

The complexity approach emphasizes the storing, or summarizing succinctly via devices such as scaling laws, as well as the predicting, aspect of the empirical foundations of science. It begins with determining standard outcomes of complex systems that occur independently of assumptions. Zipf's Law, and other power laws, are examples; complex systems seem to generate certain outcomes that match the size distribution of cities and commodity price series. The existence of such standard outcomes has significant modeling and policy implications. If there are strong selforganization forces that lead to data patterns independent of assumptions made about agents, then those assumptions don't matter and deductive theory is irrelevant.

Most economists working in complexity, including us, take the position that the forces of self-organization are not so overwhelmingly strong that deductive work is irrelevant. Insight into the patterns can be gained by studying the microfoundations of the complex system. The two approaches can complement one another. Agent based complexity models are designed to add further information; they take those predictions that follow independently of assumptions as a baseline prediction, and see what theoretically based models can add to that predictive power. The models are not totally deductive. As discussed above, since the assumptions used in these models generally cannot be judged by their predictive value, they need to reflect observed behavior-what people actually do.

(3) Logically consistent with the data being modeled.

At this point precisely what simulations are adding to our understanding is a bit unclear. There is much work to be done in determining what inferences can be drawn from simulation work. Will it be limited to general understanding of the process, or will it be more specific? At the stage of development it does seem able to help us establish some minimal restrictions on allowable models. Much of the work in simulations is currently at this stage. For example, Joshua Epstein (1999) has suggested that a minimal requirement 
of any "macroscopic explanandum" is that it can be generated by agents following the assumptions made in the model. This might be called the computable existence requirement. Work that has explored existence includes Epstein and Axtell (1996), Arthur et al. (1997) and Axelrod (1997). This existence requirement seems like a natural desideratum of a model. Its converse could also be a strong requirement of a model: If it can be proved that the assumptions of the model cannot generate the empirical results, then the model is unacceptable.

Notice that the simulation has two roles in the complexity approach: (1) as a way of testing assumptions, and (2), as a way of inducing assumptions-growing systems and finding patterns that match patterns in nature consistent with those assumptions.

(4) Consistent with the assumed information set of the researcher.

Learning and expectations play key roles in any model of a complex system. Both raise important issues in model symmetry. A desirable requirement in any model is model symmetry -the compatibility of the expectations and learning behavior of agents with the underlying foundation of the model. Strong model symmetry requires that the assumptions one makes about one's own knowledge of the model are consistent with the assumptions made about the learning behavior and expectations of the agents in the model. Rational expectations models reflect strong model symmetry with an economics of control framework, and is a reasonable requirement for applied policy models in standard welfare economics.

In the complexity approach to welfare economics, rational expectations do not meet the strong model symmetry assumption. Since the complexity approach assumes less than full knowledge on the part of the researcher, to have a model meet the model symmetry assumption requires that we assume less than full knowledge on the part of the agents in the model. Much work remains to be done in determining precisely what set of assumptions that meet strong model symmetry are best, but, as a requirement, it seems highly desirable requirement to place on models. Sargent (1993), (1999) builds models that "back off" from pure rational expectations by replacing rational expectations agents with agents who act like the scientists who study them. These type of models satisfy model symmetry as we use the term above.

One could also imagine building models of the Sargent (1993), (1999) type but where the agents are Bayesian Model Averaging (BMA) types of statisticians rather than the more "frequentist" type statisticians in Sargent's models. An example of BMA work that could be used is in Brock, W., Durlauf, S., (2000b). It applies statistical techniques, such as Bayesian Model Averaging, to deal with cases where the model is not known and the data are allowed to convert prior assessments over members of a family of plausible models into posterior assessments. It attempts to incorporate the reporting of "model uncertainty" with "confidence intervals" thereby imbedding uncertainty into policy analysis. It is plausible to believe that agents living in a model are as uncertain about the true model of the economy they are co-creating as are the scientists studying the economy. The principle of model symmetry would argue for assuming that if the scientists are BMA then the agents in the model should also be BMA. 


\section{3) The nature of the policy goals considered would be broader.}

Economic applied policy today in large part focuses heavily on allocative efficiency to the exclusion of other goals. In principle, it is recognized that there is more to welfare theory than allocative efficiency, but, in applied policy practice, little concern is actually given to other goals. This focus is a legacy of the economics of control welfare approach that could only come to definitive conclusions for efficiency. The formal limitations of the economics of control welfare framework to applied policy work are well known; to logically derive policy directives from the set of carefully specified initial conditions to policy is difficult, and significant limitations must be placed on the policy directives as to what they mean. It is for that reason that the work focuses on efficiency. Consider Von Graaf's (1963) conclusion to his celebrated study of welfare economics:

..the possibility of building a useful and interesting theory of welfare economics-i.e. one which consists of something more than the barren formalisms typified by the marginal equivalencies of conventional theory is exceedingly small.

It was criticisms such as Von Graaf's that led economics to stop working on the barren formalisms in their applied work, and to take a looser approach to assumptions made in applied policy.

In complexity welfare economics, the limitations of drawing specific policy conclusions are built into the structure of the initial policy thinking. Since one cannot even come to definitive conclusions about efficiency, it frees economics up to consider a broader range of issues. This does not mean that economics' focus on allocative efficiency would be eliminated; it would just not be the exclusive focus, as it often currently is. For example, one would expect complexity economics to deal much more with moral questions, such as those raised by Sen (2000), the systemic creation of norms and tastes raising positional goods issues such as those raised by Frank, resilience and other systemic-existence issues, such as those raised by the work in ecology. These considerations would be given an equal footing with standard efficiency considerations.

An example of the type of work we have in mind here is that done by the Resilience Network (Rnet), a group of ecologists and economists associated with the Beijer Institute of Sweden. They are unified by exploration of concepts of "resilience" where "resilience" refers to the ability of a system to restore itself when buffeted by shocks or, in the wider sense of the word, maintain its function after shocked. (See Holling (1997) or Holling, Gunderson, and Peterson (1997)).

The Rnet approach to complexity uses dynamical systems theory and nonlinear control systems theory to study the locating of patterns of spatial and temporal "lumpiness," where "space" is interpreted in a wide sense. (See, for example, Holling's (1992) paper. This attempt to simplify complexity by application of spectral analysis in time and "space" in order to identify "clumps of high spectral power" is analogous to application of spectral analysis in macroeconomics to locate regions of high spectral 
power, and is the type of work that must be done if the mathematics of complexity is to affect policy.

The underlying mathematics is complicated, but the results can be reduced to a tool simple enough to be useful to policy makers. For example the log/log space/time scaling plot of Holling(1997, p. 356), called a Stommel plot, and the adaptive cycle diagram of Holling (1997, p.389), both could be used to suggest to policy makers how much focus they should give to equilibria shifts.

Pedagogically, this broader view of welfare economics would change the way we present microeconomics. The existence of an externality would not be seen as an immediate call for policy action, since externalities would be seen as contextual to the model one is working with, not something that exists in the world. Indeed, complexitybased thinking with its emphasis on such things as slow moving unobserved variables, and latent self organization potential causing "surprises", most likely would approach policy action on a perceived externality quite gingerly. Similarly, from this broader welfare perspective, the absence of externalities would not be seen as an argument for laissez faire. The complexity-based policy analyst, much like the Rnet analyst, would constantly be on the lookout for unpleasant "surprises" caused not only by observed spillovers left out by markets, but also unobserved slow moving uncosted spillovers that may lead to very unpleasant surprises (e.g. jumps in loss of environmental quality caused by bifurcations). In short, failures of market outcomes, as well as market failures, will be part of the policy analysis.

\section{4)The Nature of the Policy Solutions Would Change}

In the economics of control policy solutions involve getting the economy to the "right price." In muddling through, there is no right price; policy solutions involve finding a "right", or at least acceptable, process. This means that policy work is more focused on institutional issues-designing institutions that are generally lead to desirable ends. Examples of right process solutions can be seen in Scott's Seeing Like a State (1998). This process view of policy gives one a different perspective on the nature of competition and the desirability of the market than does standard welfare economics. The market is a desirable institution not only because it leads to efficient results, but also because it is resilient; it allows for the change that is necessary in a complex evolving system. But the market that does this is seen as a real world institution, not as an abstract ideal, and arguments as to whether intervention into the market process is or is not desirable would have to be made contextually, in reference to the actual institutions, not theoretically, in reference to a hypothesized state of perfect competition.

The muddling through approach sees the policy process as a complex system in which any researcher is seen as part of the process, not the entire process. Thus, it would not see economists arriving at policy recommendations alone (even in principle); instead it would see economists as part of an integrated regulatory approach that uses economics, but is not fully directed by economics. In this approach economists provide advice both in the form of benefit cost/analysis and mechanism design analysis. This would especially be so on issues where preferences of economics agents are likely to be altered 
by participation in a mutually respectful interactive educative process like an idealized town meeting "teach-in".

Some policy commentators (e.g. Farber (1999)) argue that components of preferences that are invariant to such mutually educative interactive exchange processes should loom much larger in policy weightings (i.e. almost lexicographical) relative to components of preferences measured by standard economics-based methods such as benefit/cost analysis as conventionally applied. Notice how "complexity-based" our interpretation of Farber is--i.e. his "educative process invariant" components of tastes are "emergent properties" of his idealized interactive political decision process.

The result of taking a complexity approach to policy would be a combining of the expertise of economists, scientists and lawyers and a mixed approach to regulation. That mixed approach would contain elements from measures of willingness to pay, but it would also have measures of “willingness-to vote.” It would back away from approaches that only consider benefit/cost analysis, but it also would nonetheless respect the efficiency goals embodied in the benefit/cost movement. It would see the political sphere as a dynamic uniquely deliberative evolver of value systems that have a higher claim for representation in an over-all "value calculus" than private preferences.

This change would lead to some changes in regulatory processes. For example, in environmental regulation we believe there would be more focus on devices such as regulatory tiering, separation of users, "smart markets", and treatment of chunks of the ecosystem as Tieboutian local public goods, as ways of reducing the impact of the "fumbling fist" of the State and, perhaps, reducing some of the public resistance to environmental regulation.

Complexity-based methods, by focusing more on the surprise potential contained in self organization of large complex adaptive systems, would direct policy in a manner that would take care in designing institutions, i.e. changes in the "rules-of-the-game" to avoid rent seeking behavior. It would, as Magee and Brock argued (Colander, 1984) try to design economic institutions to reward invisible hand behavior more than invisible foot behavior. It would work hard to avoid wasteful policies put in place by narrow special interest "rent seeking" groups where the benefits to such groups are less than the cost to society as a whole. The reality is that many attempts at institutional design end up generating unpleasant surprises in the form of stimulating the self organization of such "rent seeking" groups. A focus of complexity based policy research would be on ways of structuring incentives for groups of agents to self organize in order to produce useful goods and services for society at large rather than self organizing to extract wealth through the use of the state.

Another change in the type of policy solution would follow from the broadening of the goals discussed above. The greater focus on norm creation would also change the nature of policy solutions considered. For example, reducing positional consumption races caused conspicuous consumption of winners of "winner-take-all" markets which was stressed by Frank and Cook (1995) and amplified by Frank (1999) would likely be more emphasized. Since the total volume of consumption pressure generated by lower 
strata of society is so huge (even relative to that of the top strata), this kind of "renorming from the top down" could have enormous impact. This is so because the rarified rich are tiny in population and even their total volume of consumption is small relative to the total volume of consumption of the classes below them.

One can only imagine the alteration of behavior that might take place if the talent of Madison Avenue were applied to educate consumers to generate behavior that minimized the load on the environment. It is easy to imagine the revenues from appropriate externality taxes would be large enough to fund potent ad campaigns.

We fully recognize that care must be taken in making any of these arguments, but the small discussion given to it relative to its potential importance suggests to us that more intensive consideration of such issues by economists would be a worthwhile applied policy investment.

\section{Conclusions}

Our discussion has been wide-ranging and highly preliminary. We do not want to claim too much for it, of for how any of the propositions offered directly follow from taking a complexity perspective. However, we believe that the topics are important, and are too little discussed by economists. Moreover, we recognize that many of the changes in method currently occurring in the profession, changes which are moving in the muddling through direction, would probably be made even if complexity had never been developed. There is a natural tendency of systems to muddle through and arrive at reasonable approaches on their own, and that has been the case in applied economic research, where the applied work had deviated significantly from its theoretical welfare foundations.

Our hope is that by highlighting the discord between the welfare theory we teach, and the actual practice of applied policy economics, researchers will become more conscious of the pragmatic approach they are taking, and embrace it, and develop it further, rather than reluctantly use it.

Economics often considers itself the queen of the social sciences. Its coronation has been associated with its formal scientific nature, it's consistency of approach, its certainty in its applied policy suggestions, and its empirical nature. Each of those elements is closely tied to the holy trilogy of assumptions, which gives an almost religious nature to the monarchy. It is this connection that accounts for why the core general equilibrium theory has remained the center of welfare economics, even as applied policy work moved away from those assumptions. There was fear that if we give up the holy trilogy we will give up our reign. That need not be true. However, if muddling through is accepted as the best we can do with welfare economics, then the economic profession's claim to being the queen cannot be a religious claim, as the holy trilogy analogy suggests it is by some researchers. Instead it would be a secular claim based on its usefulness in arriving at reasonable and workable policy solutions to the difficult policy problems we face. 


\section{Bibliography}

Akerlof, George (1993) “The Economic Consequences of Cognitive Dissonance” in International Library of Critical Writings in Economics, vol. 26. Aldershot, U.K.: Elgar.

Arthur, Brian, Stephen Durlauf, and David Lane (1997) THE EconOMY AS AN Evolving Complex System II Reading Mass. Adison-Wesley,

Axelrod, Robert, (1997) The Complexity of CoOperation: Agent-BASEd Models of COMPETITION AND COLLABORATION. Princeton: Princeton University Press.

Blume, L.E. "Populations Games” in Arthur, Brian, Stephen Durlauf, and David Lane (1997) The Economy as an Evolving Complex System II Reading Mass. AdisonWesley,

Brock, W. (2000a) In Colander, ed. THE CoMPLEXITY VISION AND THE TEACHING OF ECONOMICS, Edward Elgar.

Brock, W. (2000b), "Some Mathematical Tools for Analyzing Complex-Nonlinear Systems," SSRI W.P. 2020. (http://www.ssc.wisc.edu/ wbrock)

Brock, W.(1993) "Pathways to Randomness in the Economy: Emergent Nonlinearity and Chaos in Economics and Finance," ESTUDIOS ECONOMICOS 8(1), also http://www.ssc.wisc.edu/ wbrock)

Brock, W., Hommes, C. (1998) "Heterogeneous Beliefs and Routes to Chaos in a Simple Asset Pricing Model," JOURNAL OF ECONOMIC DYNAMICS AND CONTROL, Vol. 22, 1235-1274.]

Brock, W. and S. Carpenter (2000a) A Theory of Adaptive Management: A Bayesian Model Averaging Approach”," Department of Economics and Limnology, University of Wisconsin, Madison.

Brock, W. and S. Carpenter (2000b), "Habitat Change, Harvest and Depensation in Living Resources: Thresholds, Learning and Policy Choice," Department of Economics and Limnology, University of Wisconsin, Madison.

Brock, W. and D. Colander (2000) “Complexity and Economic Policy”, in Colander, ed. ThE COMPLEXITY Vision AND THE TEACHING OF ECONOMICS, Aldershot, U.K.: Elgar;

Brock, W., and S. Durlauf, (1995, 1997), "Discrete Choice Theory with Social Interactions, I: Theory and II: Econometrics," Department of Economics, University of Wisconsin, Madison (available at http://www.ssc.wisc.edu/ wbrock). 
Brock, W., and Durlauf, S., (1998), "A Formal Model of Theory Choice in Science," ECONOMIC THEORY, (forthcoming).

Brock. W. and S. Durlauf (2000a), "Interactions-Based Models" HANDBOOK OF ECONOMETRICS (http://www.nber.org),

Brock. W. and S. Durlauf (2000b),"Growth Economics and Reality” WORLD BANK ECONOMIC REVIEW

Day, R., and Ping Chen (1993) NONLINEAR DYNAMICS AND EVOLUTIONARY ECONOMICS, Oxford University Press.

DeLong, Brad. "What's Wrong with Our Bloody Economies?"

(http://econ161.berkeley.edu/ created 1/11/98)

Epstein, Joshua (1999) Agent-Based Computational Models and Generative Social Science, COMPLEXITY, Vol. 4. No. 5.

Epstein, Joshua and Robert Axtell (1996) Growing ArTificial Societies: Social SCIENCE FROM THE BOTTOM Up. Cambridge, Ma. MIT Press.

Farber, D., 1999, ECO-PRAGMATISM: MAKING SENSIBLE ENVIRONMENTAL DECISIONS IN AN UNCERTAIN WORLD, Chicago, The University of Chicago Press.

Frank, R., (1999), LUXURY FEVER: WHY MONEY FAILS TO SATISFY IN AN ERA OF EXCESS, New York: The Free Press.

Frank, R. and P. Cook (1995), THE WINNER-TAKE-ALL SOCIETY, New York: The Free Press.

Geweke, J., (1999), "Computational Experiments and Reality," Department of Economics, The Universities Of Iowa And Minnesota (http://www.econ.umn.edu/ geweke). Hansen, Lars,

Holling, C., (1992), "Cross-Scale Morphology, Geometry, and Dynamics of Ecosystems," ECOLOGICAL MONOGRAPHS, 62(4), pp. 447-502.

Holling, C., ed., (1997a), CONSERVATION ECOLOGY, hosted on the WWW at (http://www.consecol.org).

Holling, C., (1997b), "Simplifying the Complex: The Paradigms of Ecological Function and Structure," EUROPEAN JOURNAL OF OPERATIONAL RESEARCH, 30, 139-146.

Holling, C., Gunderson, L., Peterson, G., (1997), "Comparing Ecological and Social Systems," Department of Zoology, University of Florida. 
Judd, K., 1998, NUMERICAL METHODS IN ECONOMICS, MIT Press, Cambridge, Mass.

Kreps, David (1997) “Economics—-The Current Position” DedALus, Winter.

Lerner, Abba (1944) The EConomics of Control, MacMillan Publishers.

Magee, Steven, and W. Brock (1984) “The Invisible Foot” in Colander, (ed.) NeOClassical Political Economy. Boston, Ballinger

Peirce, Charles (1879) "Note on the Theory of the Economy of Research" in THE Writings of Charles PeirCe: A Chronological Edition, Indiana University Press 1986.

Pizer, W., (1996), MODELING LONG-TERM POLICY UNDER UNCERTAINTY, Ph.D. Thesis, Department of Economics, Harvard University.

Sargent, T., (1993), BOUNDED RATIONALITY IN MACROECONOMICS, Clarendon Press, Oxford

Sargent, T., (1999), THE CONQUEST OF AMERICAN INFLATION, Princeton University Press, Princeton, NJ.

Schumpeter (1954) HISTORY OF ECONOMIC ANALYSIS

Scott, J., (1998), SEEING LIKE A STATE: HOW CERTAIN SCHEMES TO IMPROVE THE HUMAN CONDITION HAVE FAILED, New Haven, Conn.: Yale University Press.

Sen (2000), Nobel Prize Speech AmERICAN Economic RevieW

Solow, Robert (1990) The Labor Market as a Social Institution, Cambridge Mass. And Oxford. Blackwell.

Solow, Robert, (1997) "How Did Economics Get that Way and What Way Did it Get?” DEDALUS, Winter.

Thaler, Richard (1999)

Turnovsky, S., 1995, METHODS OF MACROECONOMIC DYNAMICS, MIT Press, Cambridge, Mass.

Von Graaf (1963) TheORETICAL Welfare ECONOMICS, Cambridge, Cambridge University Press. 